\title{
Formation of a Unique 1:2 Calcium-Calixquinone Complex in Aqueous Media
}

\author{
Sun Kil Kang, One-Sun Lee, Suk-Kyu Chang, ${ }^{\dagger}$ Doo Soo Chung, Hasuck Kim, and Taek Dong Chung* \\ Department of Chemistry, Seoul National University, Seoul 151-747, Korea. *E-mail: tdchung@snu.ac.kr \\ ${ }^{\dagger}$ Department of Chemistry, Chung-Ang University, Seoul 156-756, Korea \\ Received December 3, 2010, Accepted December 26, 2010
}

\begin{abstract}
We report the complexation behavior of calix[4]arenemonoquinone-triacid (CTAQ), which is an electroactive and water-soluble receptor for calcium ion. UV-visible and NMR spectroscopic studies revealed that CTAQ in aqueous media forms 1:2 as well as 1:1 (metal ion:CTAQ) stoichiometric complexes with $\mathrm{Ca}^{2+}, \mathrm{Sr}^{2+}$, and $\mathrm{Ba}^{2+}$ ions. The nonlinear fitting of titration curves based on UV-visible absorption spectra showed that the binding constants of CTAQ for $\mathrm{Ca}^{2+}$ ion are $4( \pm 2) \times 10^{6} \mathrm{M}^{-1}$ for $1: 1$ and $1.4( \pm 0.5) \times 10^{11} \mathrm{M}^{-2}$ for $1: 2$ complex. NMR conformational studies and the titration curves corroborate that the $\mathrm{Ca}^{2+}: \mathrm{CTAQ}$ complex in aqueous solution is not present in the form of merely 1:1 one, being consistent with UV-visible spectrophotometric results. The Monte Carlo simulation supports the presence of a stable conformer of $1: 2$ complexes in which a $\mathrm{Ca}^{2+}$ ion is interposed between two CTAQs at the global minimum. This is the first model of 1:2 stoichiometric complex of calix[4]arene and alkaline earth ions in aqueous media.
\end{abstract}

Key Words : Calix[4]arenemonoquinone-triacid, Calcium ion, NMR titration, Binding constant, Monte Carlo simulation

\section{Introduction}

Calixarenes are useful macrocyclic molecules that are widely considered when we need selectively capture specific ions and molecules of our interest. The recognizing capability of calixarenes toward metal ions, particularly in size, comes from its intrinsic nature of pseudocavity-like structure of the lower or upper rim. Over the past decades, many review articles on calixarene derivatives and their complexes have been reported. ${ }^{1-5}$ Creaven et al. discussed coordination chemistry of calix[4]arenes with the functionalized lower rim and their metal complexes in terms of fluorescence, catalysis, electrochemical sensing, and biological applications. ${ }^{5}$ Danil de Namor et al. investigated complexation process between divalent cations and calix[4]arene derivatives with ester and ketone functional groups in various solvents. ${ }^{6}$ They found that the medium was a very important factor that affects complex stability and selectivity. ${ }^{7-9}$ The calix[4] arene derivatives bound with $\mathrm{Ca}^{2+}$ ion in acetonitrile while they formed no complex in methanol and $N, N$-dimethylformamide. The solvent effect on the structure of the complexes in acetonitrile and water was examined by using molecular dynamics simulation on tertbutylcalix[4]arene tetraamide ligand and its complex with metal ions. ${ }^{10}$

Host-guest interaction in aqueous media has been an attractive issue as it provides valuable insight in understanding interactions between proteins and metal ions in biological system. Investigation in non-aqueous systems hardly account for the strong desolvation and entropic benefits that are observed in water. ${ }^{11}$ To work in water, we need water soluble calixarenes and control the desired protonation state of each functional group. ${ }^{11}$ Recently, Ghoufi et al. reported host-guest assemblies of $p$-sulfonatocalix[4]arene and lanthanide ions in water into which quaternary ammonium ions were incorporated to form supramolecular assemblies. ${ }^{12}$ Despite much attention and efforts, only a few calixarene complexes with metal ions in aqueous media have been reported. ${ }^{13-17}$ As a result, very little has been known about the structure of the calixarene complexes in aqueous media.

Meanwhile, the determination of $\mathrm{Ca}^{2+}$ ion in biological system has been an attractive research theme because of its importance as a regulatory ion in physiological system. $\mathrm{Ca}^{2+}$ ion plays a critical role in the activation of enzymes, complexation with nucleic acids, nerve impulse transmission, and carbohydrate metabolism. ${ }^{18}$ Therefore, many attempts have been made to develop a better ligand that can selectively and sensitively detect $\mathrm{Ca}^{2+}$ ion in biological media. ${ }^{19-22}$ Reportedly, calixarenes containing carboxylic groups possess specific affinity to $\mathrm{Ca}^{2+}$ ion. ${ }^{20}$ This is not surprising if we remind that carboxylic groups of proteins plays a key role in binding with $\mathrm{Ca}^{2+}$ ion. It has been known that at least one coordinated carboxylate group from aspartic acid or glutamic acid side chains is normally involved in the coordination of $\mathrm{Ca}^{2+}$ ion in proteins. ${ }^{23-25}$ One of $\mathrm{Ca}^{2+}$ ion-chelating molecules, for example, the L-type $\mathrm{Ca}^{2+}$ ion channel, has four carboxylate groups. ${ }^{26-28}$ In addition, carboxylic acid group at the lower rim of a calixarene can be employed to increase the solubility of calixarene under proper $\mathrm{pH}$ condition. ${ }^{17}$ In our previous studies, we reported a water-soluble calixquinone containing carboxylic groups, which forms complex with $\mathrm{Ca}^{2+}$ ion. ${ }^{29,30}$ It showed the redox-dependent ionic recognition of self assembled calixquinone on a silver electrode, potentially applied for $\mathrm{Ca}^{2+}$ ion sensor based on its electrochemical or Raman activity. ${ }^{31}$ 


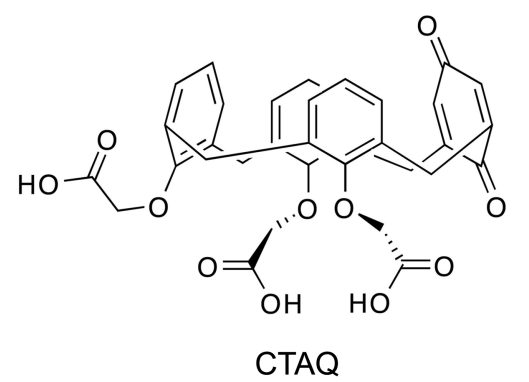

Figure 1. Molecular structure of calix[4]arenemonoquinone-triacid (CTAQ).

In this work, we looked into the stoichiometry and the structure of the complex between calix[4]arenemonoquinone-triacid (CTAQ in Figure 1) and $\mathrm{Ca}^{2+}$ ion in aqueous media using UV-visible and ${ }^{1} \mathrm{H}$ NMR spectroscopy. The complexes between CTAQ and divalent ions other than $\mathrm{Ca}^{2+}$ ion were investigated for comparison as well. Monte Carlo (MC) simulations supported the presence of the 1:2 complex and allowed better understanding on the characteristics of the interaction between $\mathrm{Ca}^{2+}$ ion and CTAQ as well as the conformation of the complex through the complex structure at the global minimum.

\section{Experimental Details}

Reagents. Water-soluble and redox-active CTAQ was synthesized by the method reported in the previous literatures. $^{29-31}$ It was prepared by the hydrolysis of the tri-tertbutylester derivatives, which was obtained by selective trialkylation of calix[4]arene with tert-butyl bromoacetate $\left(\mathrm{CaH}_{2} / \mathrm{DMF}\right)$ followed by oxidation of the phenol moiety to quinone, using $\mathrm{CF}_{3} \mathrm{CO}_{2} \mathrm{H}$ in $\mathrm{CH}_{2} \mathrm{Cl}_{2}$. The chloride salts of the alkaline earth metals were purchased from Junsei Chemicals (Tokyo, Japan). All solutions were prepared using deionized water by Nano Pure System (Barnsted). 0.1 M 4-(2-Hydroxyethyl)-piperazine-1-ethanesulfonic acid (HEPES; Aldrich) and tetraethylammonium hydroxide aqueous solution (TEAOH, 20 wt.\% in aqueous solution, Acros Organic) were used to make pH 7.4 buffer solution.

NMR Measurements. ${ }^{1} \mathrm{H}$ NMR measurements and 2DNMR experiments (COSY) were carried out using a 600 $\mathrm{MHz}$ FT NMR Spectrometer (Bruker AVANCE 600, Germany). The signal of water impurity present in $\mathrm{D}_{2} \mathrm{O}$ NMR solvent was used as internal reference for the ${ }^{1} \mathrm{H}$ chemical shifts. The complexation behavior of CTAQ toward $\mathrm{Ca}^{2+}$ ion was studied by adding calcium chloride of a known concentration into the NMR tube that contained $1.5 \mathrm{mM}$ CTAQ in $\mathrm{D}_{2} \mathrm{O}$ solvent. The $\mathrm{pH}$ of the solution was controlled by adding HEPES sodium salt corresponding to $10 \mathrm{mM}$. Increasing amounts of $\mathrm{Ca}^{2+}$ ion were added to the CTAQ solution until the change of chemical shift was ceased. All measurements were carried out at $298 \mathrm{~K}$.

UV-visible Spectrophotometry. All absorption UV-visible spectra were obtained with HP Vectra XM (personal computer) driven HP 8453 UV-visible spectrophotometer. The stoichiometry of CTAQ complex with $\mathrm{Ca}^{2+}$ ion was studied by adding a known amount of calcium chloride into the CTAQ solution in a UV-visible cell.

Monte Carlo Simulation. The AMBER* force field implemented in Macromodel 6.0 $0^{32}$ was used for the MC conformational search and molecular mechanics calculations of CTAQ and $\mathrm{Ca}^{2+}$ ion complex to obtain the minimum energy structures. The GB/SA model ${ }^{33}$ was used for the simulation and the number of structures tried in the conformational search was 1000. Energy minimization with the conjugate gradient algorithm was performed on every sampled structure to a gradient norm of less than 0.001 $\mathrm{kJ} \cdot \mathrm{mol}^{-1} \cdot \AA^{-1}$.

Binding Constant Calculation. Equations (1) and (2) were used for the calculation of binding constant of $1: 1$ and 1:2 complex of CTAQ and metal ion. The symbol: was used for the complex between CTAQ and metal ion (M) in Eqs. (1) and (2).

$$
\begin{gathered}
\mathrm{M}+\mathrm{CTAQ} \stackrel{K_{11}}{\rightleftharpoons} \mathrm{M}: \text { CTAQ } \\
\mathrm{M}: \mathrm{CTAQ}+\text { CTAQ } \stackrel{K_{12}}{\rightleftharpoons} \text { M:CTAQ } 2
\end{gathered}
$$

The binding constants for $1: 1$ and 1:2 complexes were defined as Eqs. (3) and (4).

$$
\begin{gathered}
K_{1}=K_{11}=\frac{[\mathrm{M}: \mathrm{CTAQ}]}{[\mathrm{M}][\mathrm{CTAQ}]} \\
K_{2}=K_{11} K_{12}=\frac{\left[\mathrm{M}: \mathrm{CTAQ}_{2}\right]}{[\mathrm{M}][\mathrm{CTAQ}]^{2}}
\end{gathered}
$$

The mass balance of metal ion and CTAQ gave Eqs. (5) and (6).

$$
\begin{gathered}
{[\mathrm{M}]_{\mathrm{t}}=[\mathrm{M}]+[\mathrm{M}: \mathrm{CTAQ}]+\left[\mathrm{M}: \mathrm{CTAQ}_{2}\right]} \\
{\left[\mathrm{CTAQ}_{\mathrm{t}}=[\mathrm{CTAQ}]+[\mathrm{M}: \mathrm{CTAQ}]+2\left[\mathrm{M}: \mathrm{CTAQ}_{2}\right]\right.}
\end{gathered}
$$

Eqs. (3)-(6) were rearranged to have Eqs. (7)-(9).

$$
\begin{aligned}
& {[\mathrm{CTAQ}]^{3}+\left\{K_{1} / K_{2}-[\mathrm{CTAQ}]_{\mathrm{t}}+2[\mathrm{M}]_{\mathrm{t}}\right\}[\mathrm{CTAQ}]^{2}} \\
& +\left\{1 / K_{2}+\left(K_{1} / K_{2}\right)\left([\mathrm{M}]_{\mathrm{t}}-[\mathrm{CTAQ}]_{\mathrm{t}}\right)\right\}[\mathrm{CTAQ}] \\
& -[\mathrm{CTAQ}]_{\mathrm{t}} / K_{2}=0
\end{aligned}
$$

With the solution of Eq. (7), [CTAQ] was expressed by $K_{1}$, $K_{2}$, [CTAQ], and [M]t. When [CTAQ] was substituted into Eq. (8) and (9), [M:CTAQ] and [M:CTAQ 2$]$ could be expressed by $K_{1}, K_{2},[\mathrm{CTAQ}]_{\mathrm{t}}$, and $[\mathrm{M}]_{\mathrm{t}}$ as well.

Eq. (10) shows that the absorbance can be expressed by the linear combination of [CTAQ], [M:CTAQ], and [M:CTAQ 2 ]. Combining with Eqs. (7)-(9), the absorbance could be expressed with seven parameters: $e_{0}, e_{1}, e_{2}$, [CTAQ $]_{\mathrm{t}},[\mathrm{M}]_{\mathrm{t}}, K_{1}$, and $K_{2}$, where $e_{0}, e_{1}$, and $e_{2}$ are the molar absorptivities of CTAQ, M:CTAQ, and M:CTAQ 2 , respec- 
Table 1. Absorption coefficients and apparent binding constants of alkaline earth metal ions to CTAQ. $K_{1}, K_{2}$, and $e_{2}$ were obtained by the iterative curve fitting based on the least square method with the absorbance data. The number of parenthesis is the wavelength that was used for the spectrophotometric titration in Figure 3 and Figure S1

\begin{tabular}{cccrc}
\hline Parameters & $\mathrm{Ca}^{2+}(272 \mathrm{~nm})$ & $\mathrm{Ca}^{2+}(328 \mathrm{~nm})$ & $\begin{array}{c}\mathrm{Sr}^{2+} \\
(272 \mathrm{~nm})\end{array}$ & $\begin{array}{c}\mathrm{Ba}^{2+} \\
(262 \mathrm{~nm})\end{array}$ \\
\hline$e_{0}$ & 9600 & 1500 & 9600 & 15000 \\
$e_{1}$ & 13100 & 1300 & 12400 & 16400 \\
$e_{2}$ & 24800 & 2630 & 24500 & 32000 \\
$K_{1}\left([\mathrm{M}]^{-1}\right)$ & $4( \pm 2) \times 10^{6}$ & $4( \pm 2) \times 10^{6}$ & $2 \times 10^{6}$ & $4 \times 10^{6}$ \\
$K_{2}\left([\mathrm{M}]^{-2}\right)$ & $1.4( \pm 0.5) \times 10^{11}$ & $1.4( \pm 0.5) \times 10^{11}$ & $5 \times 10^{11}$ & $1 \times 10^{11}$ \\
\hline
\end{tabular}

tively.

$$
\text { Absorbance }=e_{0}[\mathrm{CTAQ}]+e_{1}[\mathrm{M}: \mathrm{CTAQ}]+e_{2}\left[\mathrm{M}: \mathrm{CTAQ}_{2}\right](10)
$$

The value of $e_{0}$ was determined by measuring the slope of absorbance as a function of CTAQ concentration based on the Beer's law. The value of $e_{1}$, the molar absorptivity of M:CTAQ, was obtained in the presence of excess $\mathrm{Ca}^{2+}$ ion. The values of $e_{2}, K_{1}$, and $K_{2}$ were determined by the iterative curve fitting based on the least square method with the absorbance data that were recorded in the presence of various $[\mathrm{M}]_{\mathrm{t}}{ }^{34-36}$ The molar absorptivities and binding constants are listed in Table 1.

Meanwhile, the NMR titration curve is a plot of chemical shift variation against added metal ion concentration, where

$$
\delta=\delta_{0} \frac{[\mathrm{CTAQ}]}{[\mathrm{CTAQ}]_{\mathrm{t}}}+\delta_{1} \frac{[\mathrm{M}: \mathrm{CTAQ}]}{[\mathrm{CTAQ}]_{\mathrm{t}}}+\delta_{2} \frac{\left[\mathrm{M}: \mathrm{CTAQ}_{2}\right]}{[\mathrm{CTAQ}]_{\mathrm{t}}}
$$

$\delta_{0}, \delta_{1}$, and $\delta_{2}$ are the chemical shifts of CTAQ, M:CTAQ, and $\mathrm{M}: \mathrm{CTAQ}_{2}$, respectively. The value of $\delta_{1}$ was obtained in the presence of excess $\mathrm{Ca}^{2+}$ ion and $\delta_{2}$ was determined by the curve fitting using Eq. (11). ${ }^{37}$ The method used for curve fitting of NMR titration data is the same as that for UVvisible spectrophotometric titration data.

\section{Results and Discussion}

UV-visible Spectroscopy. UV-visible spectra of CTAQ in the presence of various metal ions in an aqueous HEPES buffer at $\mathrm{pH} 7.4$ are shown in Figure 2. The electronic transition $\left(n \rightarrow \pi^{*}\right)$ of the quinone at $258 \mathrm{~nm}$ is significantly perturbed by the presence of $\mathrm{Ca}^{2+}, \mathrm{Sr}^{2+}$ and $\mathrm{Ba}^{2+}$ ions while $\mathrm{Mg}^{2+}$ ion brings about no spectral changes. Previously, it was reported that $\mathrm{Ca}^{2+}$ ion is more strongly bound by quinone carbonyl group. ${ }^{38}$

On the basis of the variance in the absorbance in the spectra, spectrophotometric titrations provide quantitative information about the binding constants and the stoichiometry of the complex. ${ }^{36,39}$ Figure 3 shows titration curves obtained using two different concentrations of CTAQ. It indicates that the complex included not only 1:1 but also 1:2 (metal ion:ligand) structure. As the dotted line in Figure 3 shows, the data set of absorbance was not properly fitted by

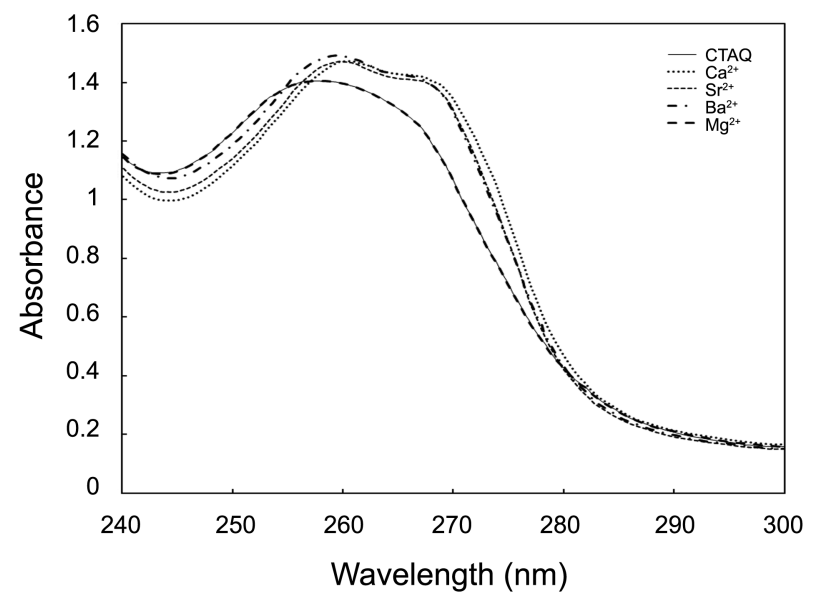

Figure 2. UV-visible absorption spectra of CTAQ in the presence of various metal ions. Absorption spectrum for $\mathrm{Mg}^{2+}$ ion and CTAQ are completely superimposed. [CTAQ] $=0.10 \mathrm{mM}$. $\left[\mathrm{MCl}_{2}\right]$ $=0.10 \mathrm{mM}$.
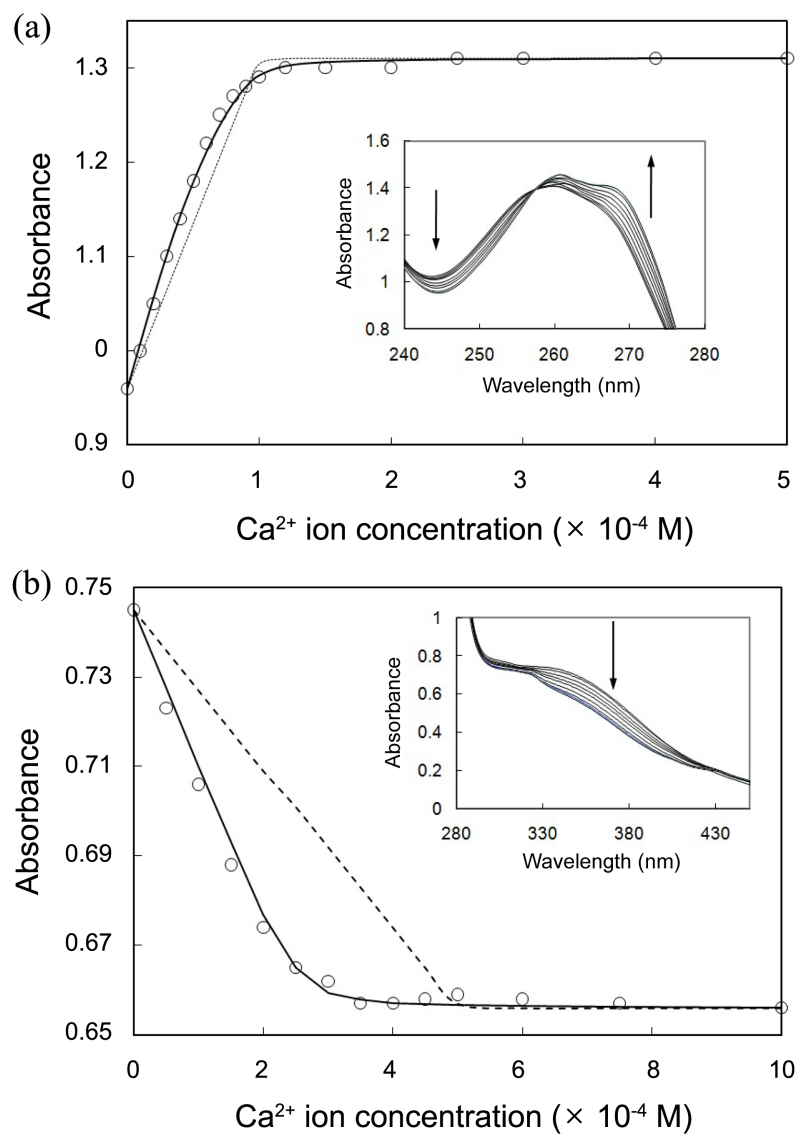

Figure 3. UV-visible spectrophotometric titration curves of (a) $0.10 \mathrm{mM}$ CTAQ and (b) $0.50 \mathrm{mM} \mathrm{CTAQ}$ with $\mathrm{Ca}^{2+}$ ion at $272 \mathrm{~nm}$ and $328 \mathrm{~nm}$, respectively, in HEPES buffer at $\mathrm{pH}$ 7.4. The dotted line was obtained by fitting the experimental data based on the model of 1:1 complex. The solid line represents the best fit obtained by assuming the presence of both $1: 1$ and 1:2 complexes.

the model based on the simple 1:1 complex. The best fit was obtained from the model assuming the presence of both 1:1 and 1:2 complexes (the solid line in Figure 3). The binding constants of $K_{1}$ and $K_{2}$ obtained from nonlinear curve fitting 

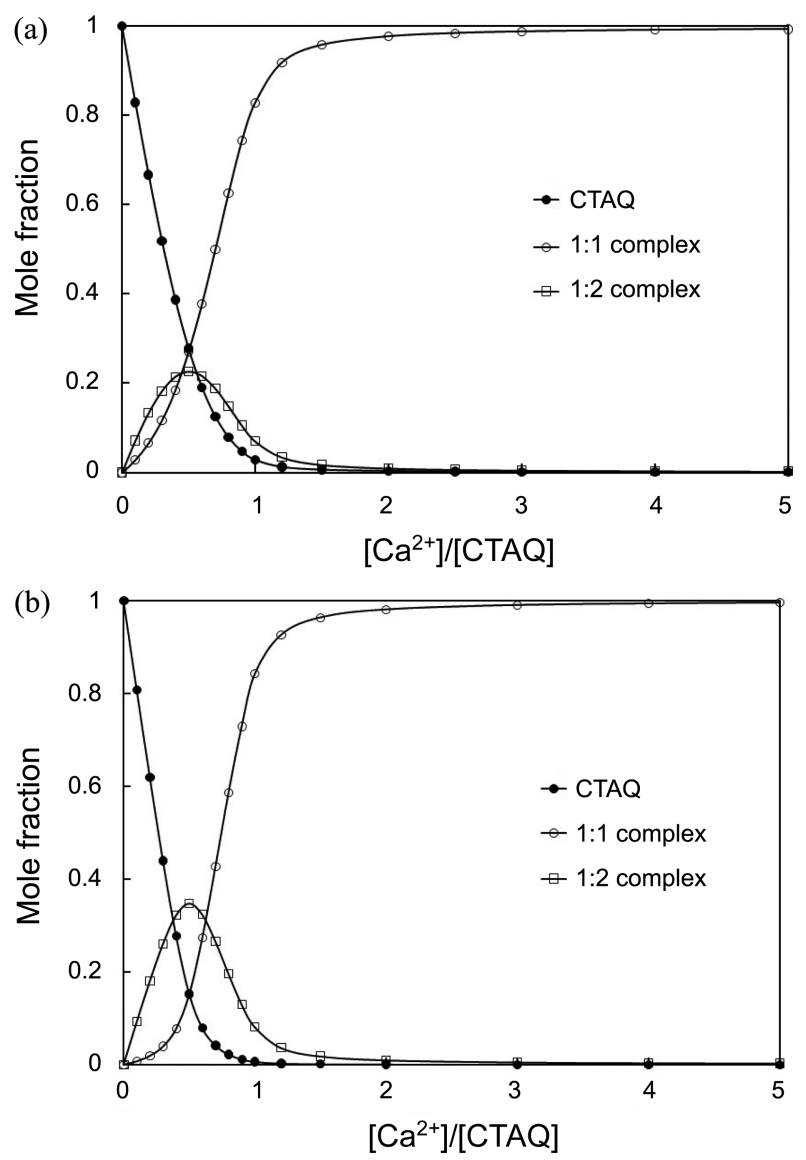

Figure 4. Concentration dependence of mole fraction of the free CTAQ, 1:1 $\left(\mathrm{Ca}^{2+}:\right.$ CTAQ) complex, and 1:2 $\left(\mathrm{Ca}^{2+}: \mathrm{CTAQ}\right)$ complex at (a) $0.10 \mathrm{mM}$ and (b) $0.50 \mathrm{mM}$ CTAQ solutions. This dependence was calculated from the binding constants $K_{1}$ and $K_{2}$ shown in Table 1.

were $4( \pm 2) \times 10^{6} \mathrm{M}^{-1}$ and $1.4( \pm 0.5) \times 10^{11} \mathrm{M}^{-2}$, respectively. The existence of 1:2 complex was more evident at higher concentration of CTAQ (Figure 3(b)). The absorbance was saturated at lower concentration of $\mathrm{Ca}^{2+}$ ion. The insets of Figure 3 show the absorption spectra of CTAQ as the amount of $\mathrm{Ca}^{2+}$ ion increases up to 2.0 equiv. The mole fractions of free CTAQ and complex species as a function of the concentration of $\mathrm{Ca}^{2+}$ ion at two different concentrations of CTAQ were calculated on the basis of the binding constants $K_{1}$ and $K_{2}$ (Figure 4). As expected, the portion of $1: 2$ complex was predominant at the higher concentration of CTAQ, $0.50 \mathrm{mM}$, in Figure 4(b), consisting well with the experimental results. The curve in a skewed bell shape indicates that the $\mathrm{Ca}^{2+}$ :CTAQ ratio is not simply $1: 1$. The maximum absorbance in the Job's plot was not on 0.5 but close to 0.6 (Figure 5). Most of CTAQ molecules are expected to be present in the form of 1:1 complex at $X_{\mathrm{CTAQ}}$ (mole fraction of CTAQ) lower than 0.5 , while appreciable amount of the 1:2 complex appears at $X_{\mathrm{CTAQ}}$ higher than 0.5 .

As aforementioned, there have been a few papers that reported complexation behavior between alkaline earth metal ions and water-soluble calixarenes but no detailed study was conducted concerning about the complexation ratio of the

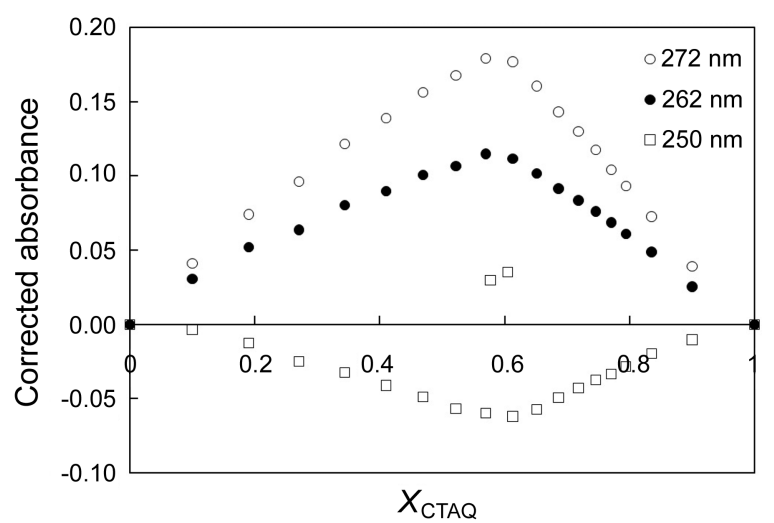

Figure 5. The Job's plot of CTAQ with $\mathrm{Ca}^{2+}$ ion in $\mathrm{pH}$ 7.4 HEPES buffer. $[\mathrm{CTAQ}]+\left[\mathrm{Ca}^{2+}\right]=0.10 \mathrm{mM} . X_{\mathrm{CTAQ}}=[\mathrm{CTAQ}] /\{[\mathrm{CTAQ}]+$ $\left.\left[\mathrm{Ca}^{2+}\right]\right\}$.

metal ions to the ligand. In aprotic media, calixarene derivatives were known to form 1:1 (metal ion:ligand) complex. ${ }^{19,20,40}$ According to the X-ray crystallographic data, ${ }^{41}$ calixquinone derivatives form 1:1 complex with metal ions. Therefore, 1:2 complex formation of CTAQ and $\mathrm{Ca}^{2+}$ ion and its structure attracts considerable interest. The same experiments with other alkali earth metal ions revealed that $\mathrm{Ba}^{2+}$ and $\mathrm{Sr}^{2+}$ ions also form complexes with 1:2 stoichiometry in addition to $1: 1$ one (Figure S1 in Supporting Information).

All results of nonlinear curve fitting are summarized in Table 1. The intriguing structure of CTAQ- $\mathrm{Ca}^{2+}$ ion complex in water was further addressed through NMR and simulation studies for in-depth understanding.

NMR Titration. Figure 6 shows the NMR spectra in the presence of various concentrations of $\mathrm{Ca}^{2+}$ ion. The assignment of the peaks was described in the Supporting Information based on ${ }^{1} \mathrm{H} \mathrm{NMR}$ and ${ }^{1} \mathrm{H}-{ }^{1} \mathrm{H}$ COSY. NMR titration results revealed the stoichiometry of the complex. Up to 0.5 equiv, all peaks became broad with up-field or down-field shift as the $\mathrm{Ca}^{2+}$ ion concentration increases. Especially, the protons under the influence of quinone moiety brought about much broader peaks. This was attributed to the restriction of the quinone rotation. The captured $\mathrm{Ca}^{2+}$ ion prevented the quinone group from rotating freely by coordinating to the quinone oxygen, resulting in a slow conformational interconversion of the quinone group on the NMR time scale.

More than 0.5 equiv of $\mathrm{Ca}^{2+}$ ion caused significant spectral change. Most of the broad peaks became sharp again, while the protons close to quinone moiety such as those of quinone, aryl, and methylene groups still produced too broad peaks to be detected even at 1.0 equiv. This observation indicates that $\mathrm{Ca}^{2+}$ ion suppressed the quinone rotation and thereby the quinone calix-ring inversion process between the cone and partial cone conformation became slowed on the NMR time scale. This result was somewhat different from what had been reported on metal ion complex of calix[4]diquinone, where metal ions lock calix[4] arenes into a cone conformation by interacting with not only the ester carbonyl 
(a)

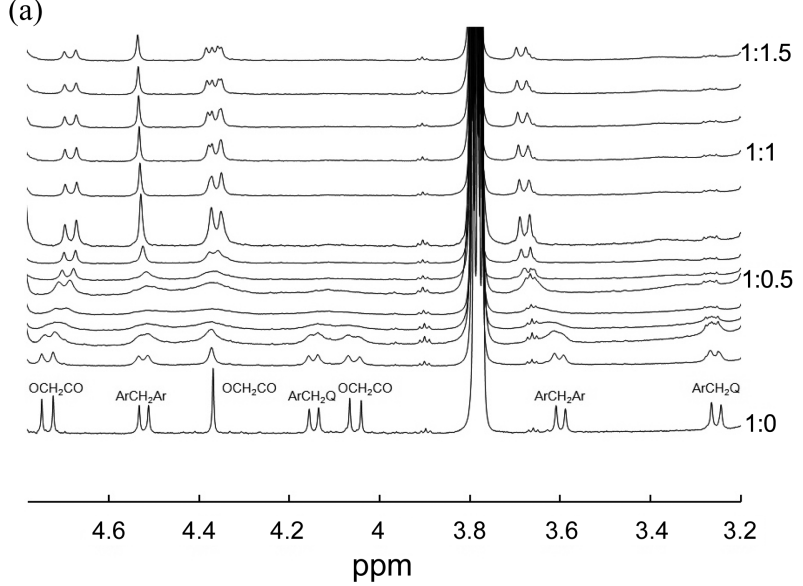

(b)

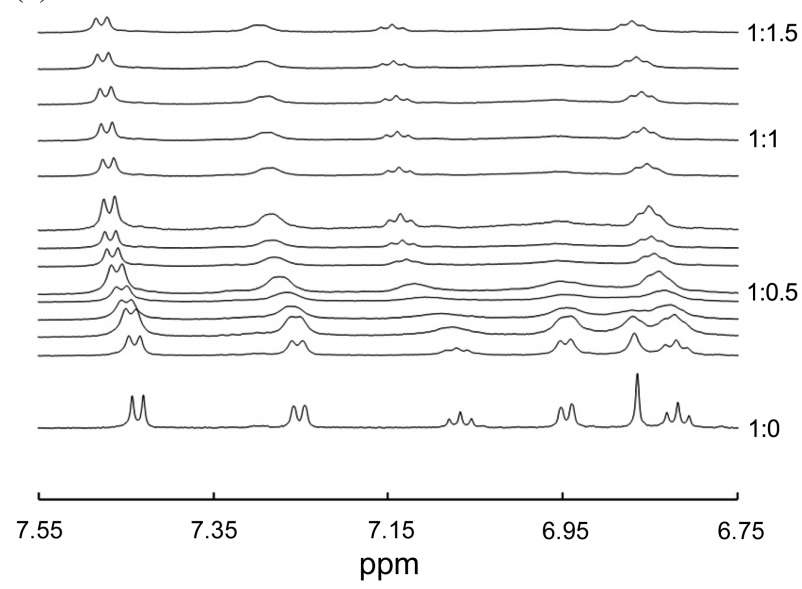

Figure 6. Chemical shifts of both (a) methylene and (b) aromatic protons of $1.5 \mathrm{mM}$ CTAQ in the absence and presence of $\mathrm{Ca}^{2+}$ ion in $\mathrm{D}_{2} \mathrm{O}$ containing $10 \mathrm{mM}$ HEPES sodium salt buffer. Molar ratio (CTAQ: $\mathrm{Ca}^{2+}$ ) are 1:0, 1:0.1, 1:0.2, 1:0.3, 1:0.4, 1:0.5, 1:0.6, 1:0.7, $1: 0.8,1: 0.9,1: 1.0,1: 1.1,1: 1.3$, and $1: 1.5$ from bottom to top.

oxygen donor but also the carbonyl group of the quinone moieties. $^{34}$

In Figure 6, another noticeable change was observed in the $\mathrm{OCH}_{2} \mathrm{CO}$ protons. In the absence of $\mathrm{Ca}^{2+}$ ion, $\delta$-values due to the $\mathrm{OCH}_{2} \mathrm{CO}$ protons are divided into two groups, which are a singlet and a pair of doublets (Supporting Information B). Upon the addition of $\mathrm{Ca}^{2+}$ ion at the higher concentration than 0.5 equiv, the singlet peak at $4.37 \mathrm{ppm}\left(\mathrm{H}_{1} / \mathrm{H}_{1}{ }^{\prime}\right.$ in Figure S2) undergoes a large downfield shift to $4.52 \mathrm{ppm}$, and the split due to the coupling of the $\mathrm{OCH}_{2} \mathrm{CO}$ protons $\left(\mathrm{H}_{2} / \mathrm{H}_{2}{ }^{\prime}\right.$ in Figure $\left.\mathrm{S} 2\right)$ becomes smaller from $0.69 \mathrm{ppm}$ to $0.32 \mathrm{ppm}$. These results also strongly imply that significant structural changes in the complex occurred around 0.5 equiv. Supposedly, the downfield shift was attributed to the coordination of $\mathrm{Ca}^{2+}$ ion to the ethereal oxygen atoms of $\mathrm{OCH}_{2} \mathrm{CO}$. The decrease of split indicates that two protons were influenced less by the quinone or the aryl ring current at a high concentration of $\mathrm{Ca}^{2+}$ ion, compared with the complex structure at the lower concentration than 0.5 equiv. In the presence of excess $\mathrm{Ca}^{2+}$ ion, the two doublets at 4.35 and $4.38 \mathrm{ppm}$ were discriminated by ${ }^{1} \mathrm{H}-{ }^{1} \mathrm{H}$ COSY experiments (Figure S4 in Supporting Information).
The magnitude of the split of chemical shifts $(\Delta \delta)$ caused by the methylene groups $\left(\mathrm{ArCH}_{2} \mathrm{Ar}\right.$ and $\left.\mathrm{ArCH}_{2} \mathrm{Q}\right)$ also allows us to see into the conformation of CTAQ. $\mathrm{As} \mathrm{Ca}^{2+}$ ion was added, the split of chemical shifts $(\Delta \delta)$ due to one methylene group $\left(\mathrm{ArCH}_{2} \mathrm{Ar}\right)$ decreased slowly from 0.92 ppm to $0.89 \mathrm{ppm}$ on the addition of 0.3 equiv of $\mathrm{Ca}^{2+}$ ion. However, the split decreased rapidly at more than 0.5 equiv of $\mathrm{Ca}^{2+}$ ion and showed a significant reduction from 0.89 ppm to $0.69 \mathrm{ppm}$ on the addition of 0.6 equiv of $\mathrm{Ca}^{2+}$ ion. Further addition led to only a little decrease and reached almost constant at more than 1.0 equiv of $\mathrm{Ca}^{2+}$ ion.

To clarify multiple complex formations between CTAQ and $\mathrm{Ca}^{2+}$ ion, NMR titration curves were obtained. Figure 7 shows chemical shifts of several protons, the peaks of which maintain sharp during the titration. The change in chemical shifts started to slow down at much less than 1.0 equiv of $\mathrm{Ca}^{2+}$ ion, implying that $\mathrm{Ca}^{2+}$ :CTAQ complex was not a simple $1: 1$ one. Determination of binding constants using chemical shifts in NMR spectra is one of the conventional methods. ${ }^{37,42,43}$ In the case of this system, the constants were too high to estimate accurately using NMR titration data. However, the relatively good fit result on the basis of the model assuming 1:1 and 1:2 complexes is significant in understanding the complexation behavior although it should be kept in mind that the absolute values of the best-fit parameters are not very reliable (Figure S5 in Supporting Information C). Interestingly, the binding constants obtained from the NMR titration were comparable to the titration results from the UV-visible spectrometry (Table S2). From the NMR titration, we confirmed that $\mathrm{Ca}^{2+}$ ion forms $\mathrm{Ca}^{2+}: \mathrm{CTAQ}_{2}$ complex as well as $\mathrm{Ca}^{2+}: \mathrm{CTAQ}$. Considering that nitrilotriacetic acid (NTA), a ligand containing three carboxylic acids, forms 1:2 complex with $\mathrm{Ca}^{2+}$ ion, ${ }^{44,45}$ the formation of $\mathrm{Ca}^{2+}: \mathrm{CTAQ}_{2}$ complex is plausible. In addition, abundant $\mathrm{Na}^{+}$ions or tetraethylammonium ions in the buffer solution are predicted to effectively compensate for any local excess charge. ${ }^{46}$

Monte Carlo Simulation. To theoretically explore the 1:2

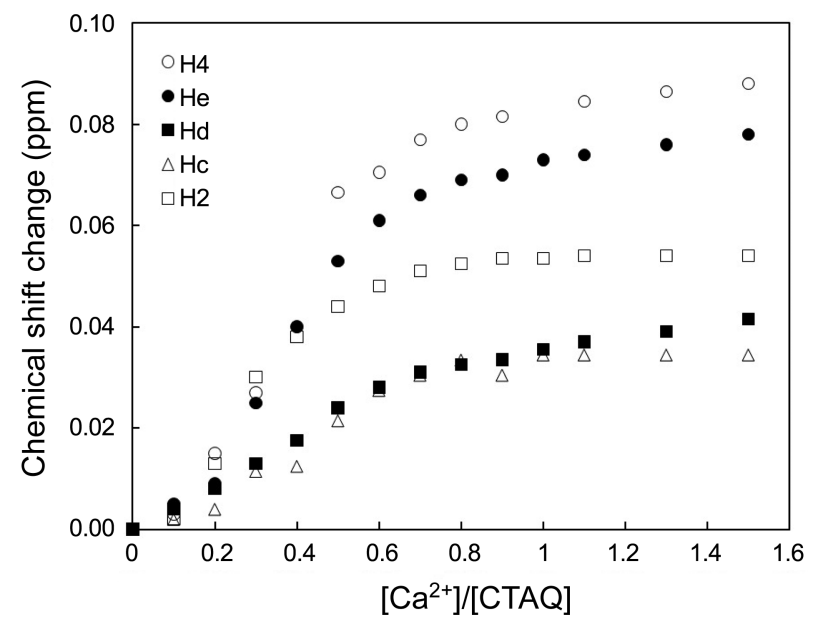

Figure 7. The chemical shifts in ${ }^{1} \mathrm{H}$ NMR spectra as a function of the concentration ratio of $\mathrm{Ca}^{2+}$ ion to $1.5 \mathrm{mM}$ CTAQ in $10 \mathrm{mM}$ HEPES-buffered $\mathrm{D}_{2} \mathrm{O}$. 


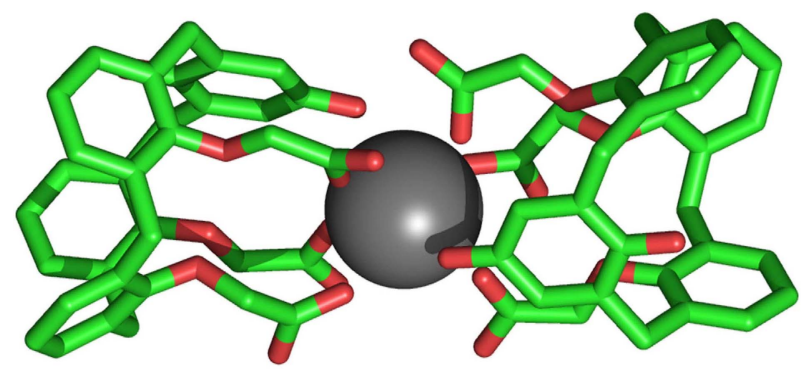

Figure 8. Global minimum structure of $1: 2\left(\mathrm{Ca}^{2+}\right.$ :CTAQ) complex obtained by $\mathrm{MC}$ simulation in water. Hydrogen atoms were omitted for the clarity.

complex of $\mathrm{Ca}^{2+}$ ion and CTAQ, MC simulation was applied to the complex of two CTAQ molecules and one $\mathrm{Ca}^{2+}$ ion in water. The global minimum structure of $1: 2\left(\mathrm{Ca}^{2+}\right.$ :CTAQ) complex found in MC simulation is shown in Figure 8. $\mathrm{A} \mathrm{Ca}^{2+}$ ion is interposed between two CTAQ molecules whereas each CTAQ molecule has a partial cone structure. As predicted from the NMR spectroscopy, a $\mathrm{Ca}^{2+}$ ion has a close contact with the quinone and carboxylic acid group of each CTAQ molecule. The partial cone structure found in $\mathrm{MC}$ simulation was consistent with the experimental result. Beer et al. conducted variable-temperature ${ }^{1} \mathrm{H}$ NMR study and demonstrated that the quinone moieties of 5,17-di-tertbutyl-26,28-bis(carboethoxymethoxy)-calix[4]diquinone (or a calix[4]diquinone) were rotating through the annulus of the calixarene at room temperature while the two aromatic rings remained fixed relative to one another. ${ }^{41}$ However, this dynamic process became slower at lower temperature on the NMR time scale and the quinone groups adopted fixed cone and partial cone conformations. A 1:2 (metal:ligand) structure has also been reported in the complex of $\mathrm{Na}^{+}$ion and calixarene. Israëli et al. reported that a $\mathrm{Na}^{+}$ion and two calix[4]arene tetraester formed a 1:2 complex in acetonitrile and chloroform mixture solvent using NMR spectroscopy. ${ }^{47}$ It was speculated that 1:2 complex of $\mathrm{Na}^{+}$ion and calixarene was an intermediate in the pathway of the exchange of $\mathrm{Na}^{+}$ ion between 1:1 complexes.

\section{Conclusion}

This is the first model of 1:2 stoichiometry of calixarenebased sensory molecule and alkaline earth metal ions in aqueous media. Concerning the composition and structure of calixquinone-based metal ion complexes in aqueous media, ${ }^{1} \mathrm{H}$ NMR and UV-visible spectroscopic studies revealed that the stoichiometry of $\mathrm{Ca}^{2+}$-CTAQ complexes was not only $1: 1$ but also $1: 2\left(\mathrm{Ca}^{2+}: \mathrm{CTAQ}\right)$ in water. The $\mathrm{MC}$ simulation showed that a $\mathrm{Ca}^{2+}$ ion of the $1: 2 \mathrm{Ca}^{2+}$ :CTAQ complex is interposed between two CTAQs and each CTAQ has a partial cone structure. The captured $\mathrm{Ca}^{2+}$ ion resides in vicinity to the carboxylic acid groups as well as the quinone group of CTAQ. By unraveling how $\mathrm{Ca}^{2+}$ ion is bound in the cavity of the CTAQ in water, this study is expected to offer valuable information for the development of ultrasensitive electrochemical and spectroscopic $\mathrm{Ca}^{2+}$-selective sensors that can be used in biological systems and give insight into synthesizing artificial ligands which play functional role like proteins.

Acknowledgments. This work was supported by the Korea Science and Engineering Foundation (KOSEF) grant funded by the Korea government (MEST) (No. R11-2007012-02002-0(2009)) and the Nano/Bio Science \& Technology Program (M10536090001-05N3609-00110) and Midcareer Researcher Program through the NRF (National Research Foundation) grant (No. 2010-0011751) of the Ministry of Education, Science and Technology (MEST) (TDC). SKK and OSL thanks to the Ministry of Education of Korea for the Brain Korea 21 fellowship.

Supplementary Materials Available. This information is available free of charge via the Internet at http://kcsnet.or.kr.

\section{References}

1. Gutsche, C. D. Calixarene. Monographs in Supramolecular Chemistry; Stoddard, J. F., Ed.; Royal Society of Chemistry: 1989.

2. Ikeda, A.; Shinkai, S. Chem. Rev. 1997, 97, 1713.

3. Danil de Namor, A. F.; Cleverley, R. M.; Zapata-Ormachea, M. L. Chem. Rev. 1998, 98, 2495.

4. Beer, P. D.; Hayes, E. J. Coord. Chem. Rev. 2003, 240, 167.

5. Creaven, B. S.; Donlon, D. F.; McGinley, J. Coord. Chem. Rev. 2009, 253, 893.

6. Danil de Namor, A. F.; Chahine, S.; Kowalska, D.; Castellano, E. E.; Piro, O. E. J. Am. Chem. Soc. 2002, 124, 12824.

7. Danil de Namor, A. F.; Jafou, O. J. Phys. Chem. B 2001, 105, 8018.

8. Danil de Namor, A. F.; Chahine, S.; Castellano, E. E.; Piro, O. E. J. Phys. Chem. B 2004, 108, 11384.

9. Danil de Namor, A. F.; Chahine, S. J. Phys. Chem. B 2005, 109, 18096.

10. Varnek, A.; Wipff, G. J. Phys. Chem. 1993, 97, 10840.

11. Biros, S. M.; Rebek, J. Jr. Chem. Soc. Rev. 2007, 36, 93.

12. Ghoufi, A.; Pison, L.; Morel, J. P.; Morel-Desrosiers, N.; Bonal, C.; Malfreyt, P. J. Phys. Chem. B 2007, 111, 11478.

13. Steemers, F. J.; Meuris, H. G.; Verboom, W.; Reinhoudt, D. N.; van der Tol, E. B.; Verhoeven, J. W. J. Org. Chem. 1997, 62, 4229.

14. Werner, T.; Kürner, J. M.; Krause, C.; Wolfbeis, O. S. Anal. Chim. Acta 2000, 421, 199.

15. Liu, Y.; Wang, H.; Wang, L.-U.; Zhang, H.-Y. Thermochim. Acta 2004, 414, 65 .

16. Bakirci, H.; Koner, A. L.; Nau, W. M. Chem. Commun. 2005, 5411.

17. Kunsági-Máté, S.; Nagy, L.; Nagy, G.; Bitter, I.; Kollár, L. J. Phys. Chem. B 2003, 107, 4727.

18. Hirning, L. D.; Fox, A. P.; McCleskey, E. W.; Olivera, B. M.; Thayer, S. A.; Miller, R. J.; Tsien, R. W. Science 1988, 268, 239.

19. Kim, Y. H.; Cha, N. R.; Chang, S. K. Tetrahedron Lett. 2002, 43, 3883.

20. Ogata, M.; Fujimoto, K.; Shinkai, S. J. Am. Chem. Soc. 1994, 116, 4505.

21. Kubo, Y.; Tokita, S.; Kojima, Y.; Osano, Y. T.; Matsuzaki, T. J. Org. Chem. 1996, 61, 3758.

22. Tsien, R. Y. Biochemistry 1980, 19, 2396.

23. Rigby, A. C.; Baleja, J. D.; Li, L.; Pedersen, L. G.; Furie, B. C.; Furie, B. Biochemistry 1997, 36, 15677.

24. Onoda, A.; Yamada, Y.; Nakayama, Y.; Takahashi, K.; Adachi, H.; Okamura, T-a.; Nakamura, A.; Yamamoto, H.; Ueyama, N.; Vyprachticky, D.; Okamoto, Y. Inorg. Chem. 2004, 43, 4447.

25. Dudev, T.; Lim, C. J. Phys. Chem. B 2004, 108, 4546. 
26. Rasmussen, H.; Barrett, P. Q. Physiol. Rev. 1984, 64, 938.

27. Heinemann, S. H.; Terlau, H.; Stiihmer, W.; Imoto, K.; Numa, S. Nature 1992, 356, 441

28. Nonner, W.; Gillespie, D.; Henderson, D.; Eisenberg, B. J. Phys. Chem. B 2001, 105, 6427.

29. Chung, T. D.; Kang, S. K.; Kim, H.; Kim, J. R.; Oh, W. S.; Chang, S. K. Chem. Lett. 1998, 1225.

30. Kang, S. K.; Chung, T. D.; Kim, H. Electrochim. Acta 2000, 45, 2939.

31. Kang, S. K.; Lee, O. S.; Chang, S. K.; Chung, D. S.; Kim, H.; Chung, T. D. J. Phys. Chem. C 2009, 113, 19981.

32. Mohamadi, F.; Richards, N. G. J.; Guida, W. C.; Liskamp, R.; Lipton, M.; Caufield, C.; Chang, G.; Hendrickson, T.; Still, W. C. J. Comput. Chem. 1990, 11, 440.

33. Qui, D.; Shenkin, P. S.; Hollinger, F. P.; Still, W. C. J. Phys. Chem. A 1997, 101, 3005.

34. Boccio, M.; Sayago, A.; Asuero, A. G. Int. J. Pharm. 2004, 284, 61.

35. Vives, M.; Gargallo, R.; Tauler, R. Anal. Chim. Acta 2000, 424, 105.
36. Wang, Z-X.; Jiang, R-F. FEBS Lett. 1996, 392, 245.

37. Ishikawa, S.; Neya, S.; Funasaki, N. J. Phys. Chem. B 1998, 102, 2502.

38. Kubo, Y.; Tokita, S.; Kojima, Y.; Osano, Y. T.; Matsuzaki, T. J. Org. Chem. 1996, 61, 3758.

39. Afkhami, A.; Khajavi, F.; Khanmohammadi, H. J. Chem. Eng. Data 2009, 54, 866.

40. Kang, S. K.; Kim, H.; Kim, J. Curr. Appl. Phys. 2009, 9, e256.

41. Beer, P. D.; Gale, P. A.; Chen, Z.; Drew, M. G. B.; Heath, J. A.; Ogden, M. I.; Powell, H. R. Inorg. Chem. 1997, 36, 5880.

42. Liu, Y.; Han, B. H.; Zhang, H. Y. Curr. Org. Chem. 2004, 8, 35.

43. Ramstad, T.; Hadden, C. E.; Martin, G. E.; Speaker, S. M.; Teagarden, D. L.; Thamann, T. J. Int. J. Pharm. 2005, 296, 55.

44. Dweck, D.; Reyes-Alfonso, A.; Potter, J. D., Jr. Anal. Biochem. 2005, 347, 303.

45. Souaya, E. R.; Hanna, W. G.; Ismail, E. H.; Milad, N. E. J. Coord. Chem. 2004, 57, 825.

46. Kang, J.-G.; Kang, H.-J.; Jung, J.-S.; Yun, S. S.; Kim, C.-H. Bull. Korean Chem. Soc. 2004, 25, 852.

47. Israëli, Y.; Detellier, C. J. Phys. Chem. B 1997, 101, 1897. 